\title{
Role of inducible nitric oxide synthase on the development of virus-associated asthma exacerbation which is dependent on Th1 and Th17 cell responses
}

Tae-Seop Shin ${ }^{1 *}$, Byung-Jae Lee ${ }^{2 *}$, You-Me Tae', You-Sun Kim ${ }^{1}$, Seong Gyu Jeon ${ }^{1}$, Yong Song Gho', Dong-Chull Choi ${ }^{2}$ and Yoon-Keun Kim ${ }^{1,3}$

\author{
${ }^{1}$ Department of Life Science \\ Division of Molecular and Life Sciences \\ Pohang University of Science and Technology (POSTECH) \\ Pohang 790-784, Korea \\ 2Department of Internal Medicine \\ Samsung Medical Center \\ Sungkyunkwan University School of Medicine \\ Seoul 135-710, Korea \\ ${ }^{3}$ Corresponding author: Tel, 82-54-279-2125; \\ Fax, 82-54-279-8449; E-mail, juinea@postech.ac.kr \\ *These authors contributed equally to this work. \\ DOI 10.3858/emm.2010.42.10.072
}

Accepted 14 September 2010

Available Online 15 September 2010

Abbreviations: AP-CAV, a fusion peptide of the caveolin-1 scaffolding domain with the Antennapedia internalization sequence from the Drosophila Antennapedia homeodomain; BAL, bronchoalveolar lavage; dsRNA, double-stranded RNA; L-NAME, $\mathrm{N} \omega$-nitro-L-arginine methyl ester hydrochloride; NOS, nitric oxide synthase; OVA, ovalbumin; PAMP, pathogen-associated molecular pattern; poly(l:C), polyinosine-polycytidylic acid; WT, wild-type; 1400 $\mathrm{W}, \mathrm{N}$-(3-aminomethyl)benzylacetamidine

\begin{abstract}
Asthma is characterized by airway inflammation induced by immune dysfunction to inhaled antigens. Although respiratory viral infections are the most common cause of asthma exacerbation, immunologic mechanisms underlying virus-associated asthma exacerbation are controversial. Clinical evidence indicates that nitric oxide (NO) levels in exhaled air are increased in exacerbated asthma patients compared to stable patients. Here, we evaluated the immunologic mechanisms and the role of NO synthases (NOSs) in the development of virus-associated asthma exacerbation. A murine model of virus-associated asthma exacerbation was established using intranasal challenge with ovalbumin (OVA) plus dsRNA for 4 weeks in mice sensitized with OVA plus dsRNA. Lung
\end{abstract}

infiltration of inflammatory cells, especially neutrophils, was increased by repeated challenge with OVA plus dsRNA, as compared to OVA alone. The neutrophilic inflammation enhanced by dsRNA was partly abolished in the absence of IFN-gamma or IL-17 gene expression, whereas unaffected in the absence of IL-13. In terms of the roles of NOSs, dsRNA-enhanced neutrophilic inflammation was significantly decreased in inducible NOS (iNOS)-deficient mice compared to wild type controls; in addition, this phenotype was inhibited by treatment with a non-specific NOS inhibitor (L-NAME) or an specific inhibitor (1400 W), but not with a specific endothelial NOS inhibitor (AP-CAV peptide). Taken together, these findings suggest that iNOS pathway is important in the development of virus-associated exacerbation of neutrophilic inflammation, which is dependent on both Th1 and Th17 cell responses.

Keywords: asthma; interferon- $\gamma$; interleukin-17; neutrophils; nitric oxide synthase type Il; RNA viruses; Th1 cells

\section{Introduction}

The development of asthma is linked not only with respiratory allergen sensitization but also with viral respiratory tract infections in early childhood (Sigurs et al., 2005; Thomsen et al., 2009). The respiratory tract is commonly infected by a range of viruses, and double-stranded (ds) RNA is a pathogen-associated molecular pattern (PAMP) expressed by many viruses during their replicative cycles (Yang et al., 1995; Guillot et al., 2005). Antiviral immune responses have innate and adaptive components; dsRNA stimulates innate immune responses via pattern-recognition receptors (PRRs), including Toll-like receptor 3 (TLR3), which result in the production of pro-inflammatory and immunomodulatory mediators, such as type I interferons (e.g., IFN- $\alpha$ and IFN- $\beta$ ), IFN- $\gamma$, and IL-12 (Alexopoulou et al., 2001; Kulka et al., 2004; Kato et al., 2006). Recently, we developed a novel asthma model that mimics virus-associated asthma; this model is characterized by neutrophilic inflammation induced by sensitization with al- 
lergens and dsRNA and is in part dependent upon type I helper T (Th1) cell response (Jeon et al., 2007b). There is increasing evidence that neutrophilic inflammation contributes to the pathophysiology of asthma exacerbation associated with viral infections (Jatakanon et al., 1999). Therefore, it is worthwhile to elucidate the precise molecular mechanisms underlying the development of virusassociated asthma exacerbation and to discover therapeutic targets.

Mild and moderate asthma are related to eosinophilic inflammation, whereas severe asthma is associated with neutrophilic (or non-eosinophilic) inflammation (Busse and Lemanske, 2001; Kim et al., 2007; Bateman et al., 2008). Eosinophilic inflammation represents Th2 cell response, whereas neutrophilic inflammation may be related to Th1 or Th17 cell responses (Kim et al., 2007, 2009). However, the precise immunologic mechanisms of neutrophilic inflammation seen in asthma exacerbation during respiratory viral infections are controversial.

Nitric oxide (NO) is a reactive, free radical gas that is produced by diverse cells via the activation of nitric oxide synthases (NOSs). All three known NOS isoforms are expressed within airways and mediate various functions, including innate host defense (Karupiah et al., 1993). In general, endothelial NOS (eNOS) and neuronal NOS (nNOS) are expressed under physiologic conditions, whereas inducible NOS (iNOS) is upregulated in the presence of pro-inflammatory factors, such as IFN- $\gamma$, VEGF, and TNF- $\alpha$ (Chesrown et al., 1994; Dembinska-Kiec et al., 1997). The NO levels in the airways are increased in asthma animal models, as well as in patients with asthma (Kharitonov et al., 1995; Weicker et al., 2001). Measurement of exhaled NO has been suggested as being helpful in the monitoring of airway inflammation in asthma, especially in the case of exacerbated asthma (Harkins et al., 2004). However, the role of NO or NOS-mediated effects in the development of asthma exacerbation during viral infections remains controversial.

In the present study, we hypothesized that both Th1 and Th17 cell responses are important in the development of virus-associated asthma exacerbation and that NOSs could be used as novel therapeutic targets against this condition. The evidence that viral respiratory tract infections exacerbate asthma severity suggested that airway allergen challenge in combination with the viral PAMP dsRNA might induce severe inflammation, as compared to inhalation of the allergen alone. To test this hypothesis, we first established a murine model of asthma exacerbation that involved al- lergen challenge with dsRNA, and we then evaluated the underlying immunologic mechanisms for the development of lung inflammation. Next, we used pharmacologic and transgenic approaches to discover therapeutic targets against the virusassociated asthma exacerbation, and then we performed target validation with drug candidates in our novel model of asthma exacerbation.

\section{Results}

\section{Role of viral PAMP dsRNA in the development of allergic inflammation}

It is known that respiratory viral infections aggravate asthma severity (Jatakanon et al., 1999). We evaluated the effects of a viral PAMP, dsRNA, on the development of allergic inflammation in a virus-associated asthma model described previously (Jeon et al., 2007b). Thus, 6-week-old wildtype (WT) C57BL/6 mice were sensitized with allergen (ovalbumin, OVA) and synthetic dsRNA [polyinosine-polycytidylic acid, poly(I:C)], subsequently challenged with OVA with or without poly(I:C) for 4 weeks, and evaluated $48 \mathrm{~h}$ after the final allergen challenge, as shown in Figure $1 \mathrm{~A}$. Cellularity in bronchoalveolar lavage (BAL) fluids showed that lung infiltration of inflammatory cells, such as macrophages, lymphocytes, and neutrophils, was enhanced in the OVA-challenged mice, as compared to the PBS-challenged mice, and that this inflammation was more aggravated by challenge with OVA + poly $(I: C)$ than with OVA alone (Figure 1B). Lung histology showed that airway infiltration of inflammatory cells was markedly enhanced in the OVA + poly $(I: C)$-challenged mice, as compared to the OVA-challenged mice (Figure 1C). Interestingly, repeated challenge with OVA + poly $(I: C)$ induced parenchymal inflammation and alveolar destruction (Figure 1C).

\section{Infiltration of Th1, Th17, and Th2 cells in the virus-associated asthma exacerbation model}

With regard to lung infiltration by Th1, Th17, and Th2 cells, the expression levels of IFN- $\gamma$ and IL-17 by lung CD3+ cells were higher in the OVA - or OVA + poly(I:C)-challenged mice than in the PBSchallenged mice (Figure 2A). Moreover, the expression levels of these cytokines by lung CD3+ cells were further increased by OVA + poly $(I: C)$ challenge, as compared to challenge with OVA alone (Figure 2A). In addition, the expression of IL-17 was increased in lung CD3- cells by challenge with OVA + poly $(\mathrm{I}: \mathrm{C})$, as compared to OVA 
A

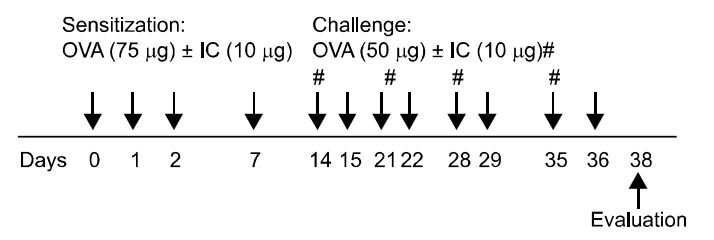

B
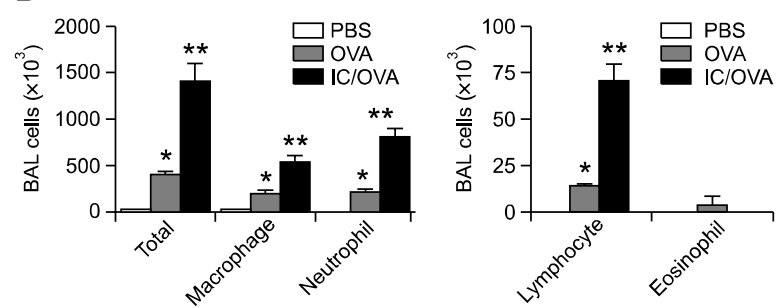

C

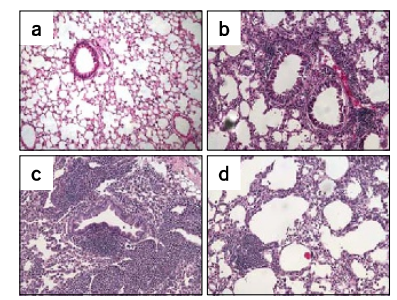

Figure 1. Repeated allergen challenge with the viral PAMP dsRNA $[$ poly $(\mathrm{I}: \mathrm{C}), \mathrm{IC}]$ induces severe neutrophilic inflammation in the lung. In all the experiments: PBS, mice sensitized with OVA and challenged with PBS; OVA, mice sensitized with OVA + poly(I:C) and then challenged with OVA; IC/OVA, mice sensitized and then challenged with OVA + poly $(l: C)$. Five mice in each group were evaluated $48 \mathrm{~h}$ after the final allergen challenge; ${ }^{*}, P<.05$ compared to the PBS group; ${ }^{* *}, P<.05$ compared to the other groups. (A) Study protocol. \#, Challenge with OVA + poly $(\mathrm{l}: \mathrm{C})$. (B) BAL cellularity. (C) Representative lung histologies (a, PBS; b, OVA; $c$ and d, IC/OVA; H\&E staining, original magnification $\times$ 200).

challenge alone (Figure 2A). However, the expression levels of IL-4 in lung CD3+ and CD3- cells were not enhanced in the OVA - or OVA + poly $(\mathrm{l}: \mathrm{C})$-challenged mice, as compared with the PBS-challenged mice (data not shown). Regarding the production of pro-inflammatory mediators, the levels of IP-10 and TGF- $\beta 1$ were significantly higher in the OVA - or OVA + poly $(\mathrm{I}: \mathrm{C})$-challenged mice than in the PBS-challenged mice, and the production levels of these mediators were further enhanced by challenge with OVA + poly $(I: C)$, as compared to challenge with OVA alone (Figure 2B). Taken together, these data suggest that repeated airway exposure to dsRNA in combination with allergens enhances neutrophilic inflammation compared to exposure to allergen alone, which is accompanied by enhanced infiltration of Th1 and Th17 cells in the lung.
A

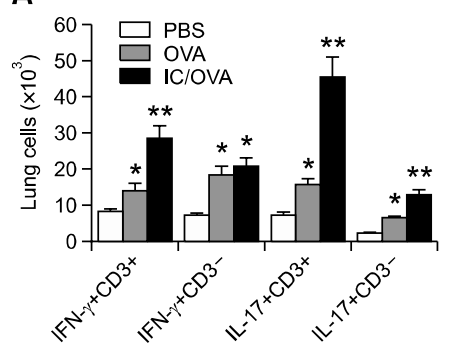

B

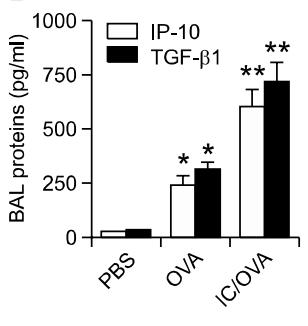

Figure 2. Repeated allergen challenge with dsRNA enhances both Th1 and Th17 cell responses in the lung. In all the experiments: PBS, mice sensitized with OVA and challenged with PBS; OVA, mice sensitized with OVA + poly $(\mathrm{l}: \mathrm{C})$ and then challenged with OVA; IC/OVA, mice sensitized and then challenged with OVA + poly $(\mathrm{I}: \mathrm{C})$. Five mice in each group were evaluated $48 \mathrm{~h}$ after the final allergen challenge; ${ }^{*}, P<.05$ compared to the PBS group; ${ }^{* *}, P<.05$ compared to the other groups. (A) Numbers of IFN- $\gamma$ - and IL-17-producing CD3+ and CD3-cells in the lung tissues. (B) Levels of IP-10 and TGF- $\beta 1$ in the BAL fluids.

\section{Role of Th1, Th17, and Th2 cell responses in the development of the virus-associated asthma exacerbation}

Based on the finding that neutrophilic inflammation enhanced by challenge with dsRNA is associated with increases in the activities of Th1 and Th17 cells in the lung, we assessed the role of helper $T$ cell subsets in the development of dsRNAenhanced neutrophilic inflammation using transgenic approach. In terms of the role of Th1 cells in the development of the dsRNA-enhanced neutrophilic inflammation, BAL cellularity analyses showed that lung infiltration of macrophages, lymphocytes, and neutrophils was significantly lower in IFN- $\gamma$-deficient mice challenged with OVA + poly $(\mathrm{l}: \mathrm{C})$ than in WT mice challenged in the same manner, although eosinophilic infiltration was enhanced in the former group (Figure 3A). In terms of the effects of IFN- $\gamma$ on the production of pro-inflammatory mediators enhanced by OVA + poly $(I: C)$ challenge, the levels of IP-10 in the BAL fluids were negligible, the levels of TGF- $\beta 1$ were increased in the IFN- $\gamma$-deficient mice compared with the WT mice, and the BAL TNF- $\alpha$ levels were similar in the two groups (Figure 3B).

With regard to the role of the Th17 cells in the development of the dsRNA-enhanced neutrophilic inflammation, BAL cellularity analysis showed that lung infiltration of macrophages, lymphocytes, and neutrophils was lower in the IL-17-deficient mice than in the WT mice, although the levels of eosinophilic infiltration were similar between the two groups (Figure $3 \mathrm{C}$ ). As for the production of pro-inflammatory mediators enhanced by challenge with OVA + poly $(\mathrm{I}: \mathrm{C})$, the levels of TNF- $\alpha$ in the BAL fluids were significantly lower in the IL- 

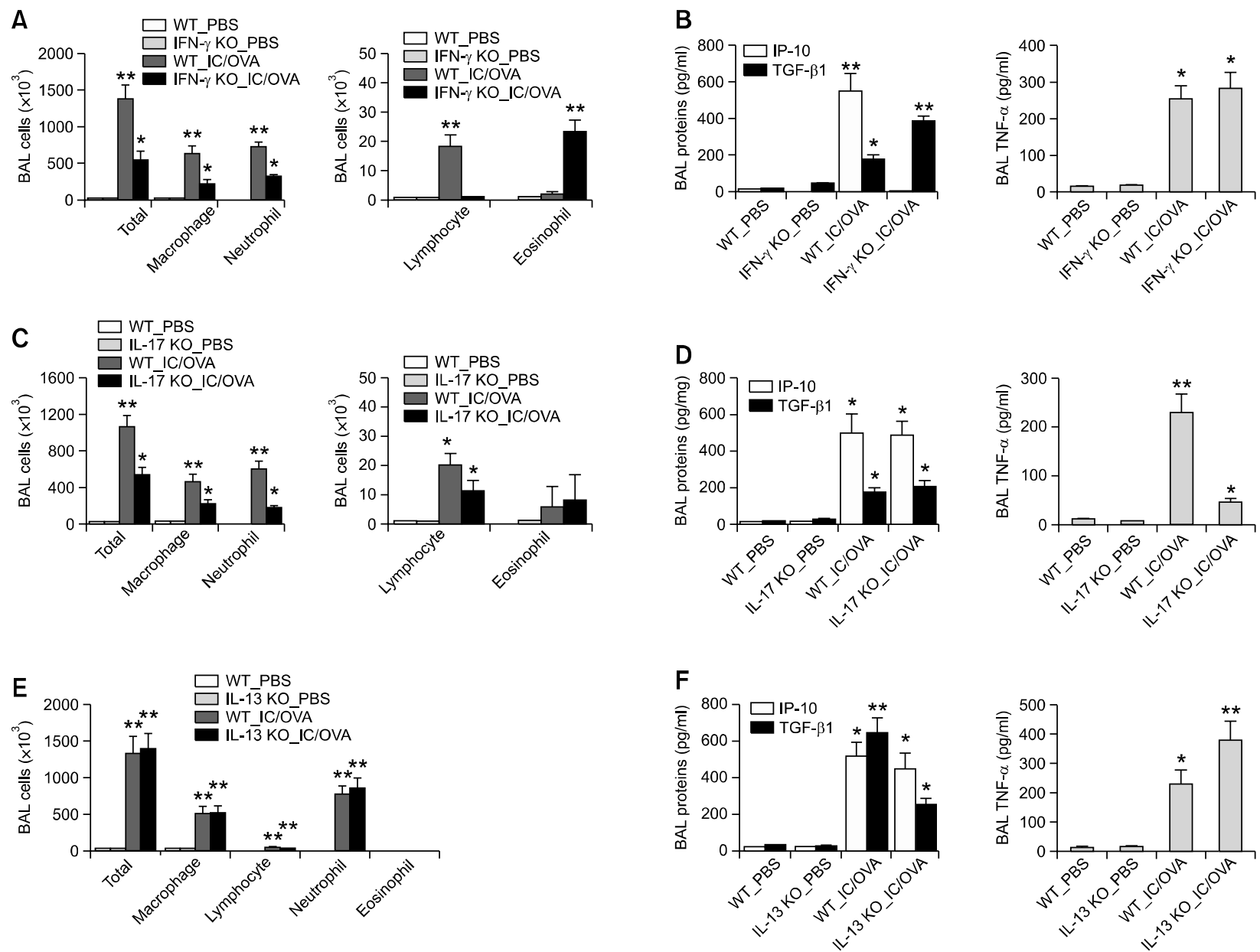

Figure 3. Lung inflammation induced by repeated allergen challenge in combination with dsRNA is dependent upon both IFN- $\gamma$ - and IL-17-mediated effects, but not on IL-13. Evaluation ( $n=5$ per group) was performed $48 \mathrm{~h}$ after the final allergen challenge. PBS, mice sensitized with OVA and then challenged with PBS; IC/OVA, mice sensitized and then challenged with OVA + poly(I:C). (A) BAL cellularity in IFN- $\gamma$-deficient and WT (both BALB/c background) mice. (B) The levels of IP-10 and TGF- $\beta 1$ (left panel) and TNF- $\alpha$ (right panel) in the BAL fluids of IFN- $\gamma$-deficient and WT mice. (C) BAL cellularity in the IL-17A-deficient and WT (both BALB/c background) mice. (D) The levels of IP-10 and TGF- $\beta 1$ (left panel) and TNF- $\alpha$ (right panel) in the BAL fluids of IL-17A-deficient and WT mice. (E) BAL cellularity in the IL-13-deficient and WT (both C57BL/6 background) mice. (F) Levels of IP-10 and TGF- $\beta 1$ (left panel) and TNF- $\alpha$ (right panel) in the BAL fluids of the IL-13-deficient and WT mice. For all figures, ${ }^{*}, P<.05$ compared to the PBS groups; ${ }^{* *}, P<$ .05 compared to the other groups.

17-deficient mice than in the WT mice, whereas the BAL IP-10 and TGF- $\beta 1$ levels were similar among the two groups (Figure 3D).

We also evaluated the role of Th2 cells in the development of dsRNA-enhanced neutrophilic inflammation. Based on the evidence that IL-13 is a key mediator in the development of Th2 asthma (Grunig et al., 1998), the severe asthma model was applied to IL-13-deficient mice. BAL cellularity analysis showed that lung infiltration of inflammatory cells enhanced by challenge with OVA + poly(I:C) was similar between the IL-13-deficient and WT mice (Figure 3E). As for the production of pro-inflammatory mediators after OVA + poly(I:C) challenge, the levels of IP-10 and TNF- $\alpha$ in the BAL fluids were similar between the IL-13-deficient and WT mice, although the BAL TGF- $\beta 1$ levels were lower in the former group (Figure $3 F$ ).

Taken together, these data indicate that neutrophilic inflammation enhanced by dsRNA relies on both Th1 and Th17 cell responses, but not on Th2 cell responses.

\section{Role of NOSs on the development of neutrophilic inflammation in the virus-associated severe asthma model}

It has been suggested that the levels of exhaled NO reflect disease severity and exacerbation in patients with asthma (Smith et al., 2005). The production of $\mathrm{NO}$ is up-regulated by IFN- $\gamma$ and TNF- $\alpha$ (Chesrown et al., 1994; Dembinska-Kiec et 

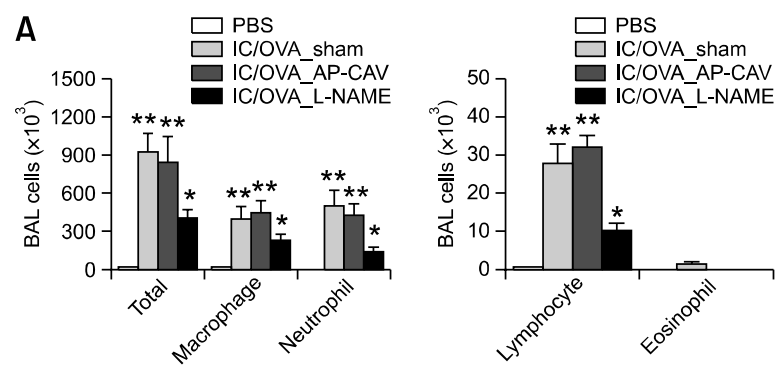

B

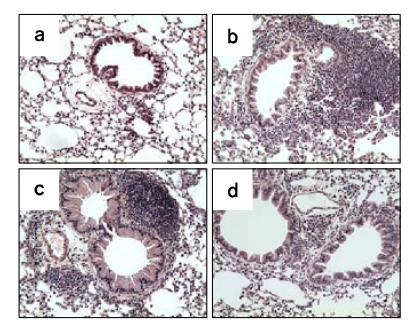

\section{C}
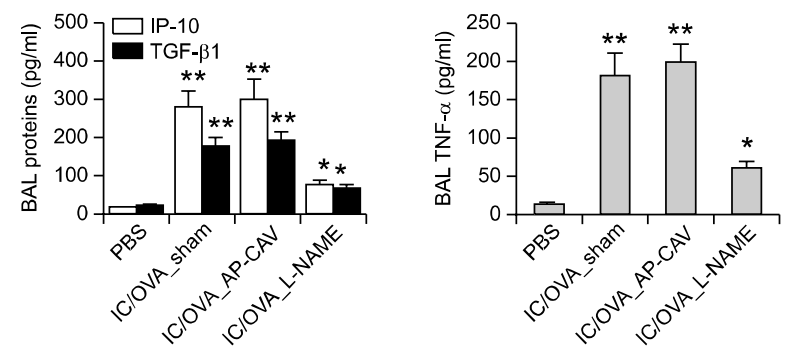

Figure 4. Treatment with a non-specific NOS inhibitor (L-NAME), but not with an eNOS inhibitor (AP-CAV), inhibits lung inflammation induced by repeated allergen challenge with dsRNA. In all the experiments, the evaluation ( $n=5$ per group) was performed $48 \mathrm{~h}$ after the final allergen challenge; PBS, mice sensitized with OVA and then challenged with PBS; IC/OVA, mice sensitized and then challenged with OVA + poly(I:C); ${ }^{*}, P$

.05 compared to PBS; ${ }^{* *}, P<.05$ compared to the other groups. (A) BAL cellularity after treatment with AP-CAV $(1 \mathrm{mg} / \mathrm{kg})$ and L-NAME (10 $\mathrm{mg} / \mathrm{kg}$ ) during allergen challenge. (B) Representative lung histologies (a, PBS; b, IC/OVA_sham; c, IC/OVA_AP-CAV; d, IC/OVA_L-NAME; H\&E staining, original magnification $\times 200)$. (C) The levels of IP-10 and TGF- $\beta 1$ (left panel) and TNF- $\alpha$ (right panel) in the BAL fluids.

al., 1997). This led us to evaluate NOSs as therapeutic targets for virus-associated asthma exacerbation. Thus, mice with virus-associated asthma exacerbation were treated with a nonselective NOS inhibitor ( $\mathrm{N} \omega$-Nitro-L-arginine methyl ester hydrochloride, L-NAME, $10 \mathrm{mg} / \mathrm{kg}$ ) or a specific eNOS inhibitor (a fusion peptide of the caveolin-1 scaffolding domain with the Antennapedia internalization sequence from the Drosophila Antennapedia homeodomain, AP-CAV, $1 \mathrm{mg} / \mathrm{kg}$ ). $\mathrm{BAL}$ cellularity analyses showed that lung infiltration of inflammatory cells was significantly inhibited by treatment with L-NAME, but not with AP-CAV (Figure 4A). Representative lung histo- logies showed that peribronchiolar and perivascular inflammation induced by challenge with OVA + poly $(\mathrm{I}: \mathrm{C})$ was reduced by treatment with L-NAME, but not with AP-CAV (Figure 4B). In terms of the production of downstream mediators of Th1 and Th17 cytokines, the levels of IP-10, TGF- $\beta 1$, and TNF- $\alpha$ in the BAL fluids were significantly inhibited by L-NAME treatment, as compared to sham or AP-CAV treatment (Figure $4 \mathrm{C})$. These data suggest that NOSs other than eNOS play an important role in the development of virus-associated asthma exacerbation and that these are good therapeutic targets for this condition.

\section{Role of iNOS in the development of neutrophilic inflammation in the virus-associated asthma exacerbation model}

Based on the finding that dsRNA-enhanced neutrophilic inflammation was inhibited by treatment with the non-specific NOS inhibitor (LNAME), but not with the specific eNOS inhibitor AP-CAV, we used a transgenic approach to evaluate the potential of iNOS as a therapeutic target for the virus-associated asthma exacerbation. Thus, the virus-associated asthma exacerbation model was applied to iNOS-deficient mice. Analyses of BAL cellularity showed that lung infiltration of inflammatory cells was significantly decreased in the absence of iNOS gene expression (Figure 5A). Representative lung histologies showed that peribronchiolar and perivascular inflammation induced by challenge with OVA + poly (I:C) was lower in the iNOS-deficient mice than in the WT mice (Figure $5 \mathrm{~B}$ ). With regard to the production of downstream pro-inflammatory mediators after OVA + poly $(\mathrm{I}: \mathrm{C})$ challenge, the levels of IP-10, TGF- $\beta 1$, and TNF- $\alpha$ in the BAL fluids were significantly lower in the iNOS-deficient mice than in the WT mice (Figure 5C). Taken together, these findings indicate that iNOS is a good therapeutic target for the virus-associated asthma exacerbation.

\section{Target validation with a specific iNOS inhibitor (1400 W) for the treatment of the virus-associated asthma exacerbation}

We validated iNOS as a therapeutic target against the virus-associated asthma exacerbation using candidate drugs. Thus, mice with virus-associated asthma exacerbation were treated with a specific iNOS inhibitor [N-(3-aminomethyl)benzylacetamidine, $1400 \mathrm{~W}, 1 \mathrm{mg} / \mathrm{kg}$ and $5 \mathrm{mg} / \mathrm{kg}$ ] during challenge. Analyses of BAL cellularity showed that 

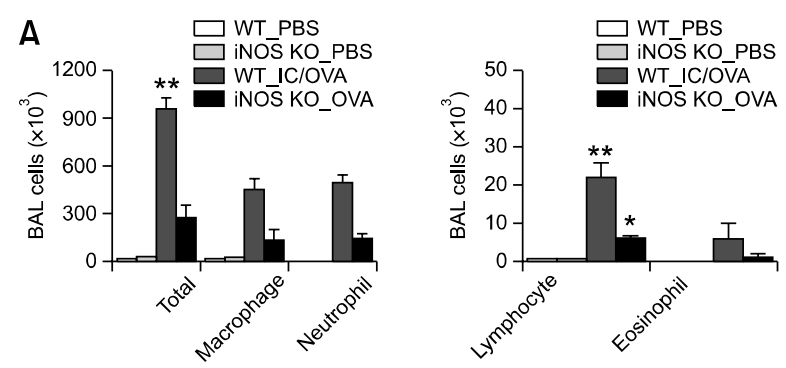

B

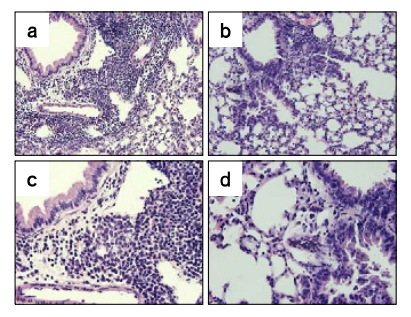

\section{C}
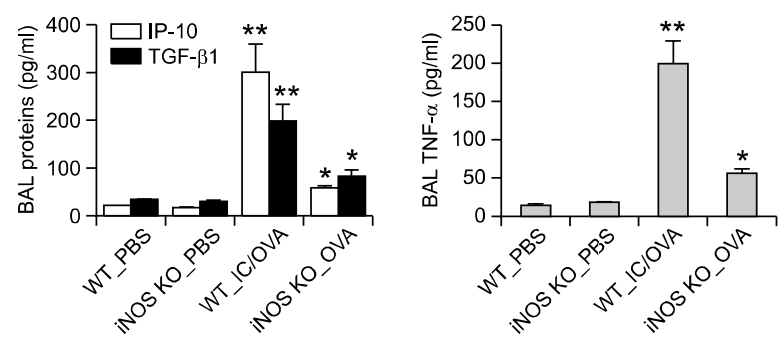

Figure 5. Virus-associated severe inflammation in the lung is abolished in the absence of iNOS gene expression. In all the experiments, evaluation ( $n=5$ per group) was performed $48 \mathrm{~h}$ after the final allergen challenge; PBS, mice sensitized with OVA and challenged with PBS; IC/OVA, mice sensitized and challenged with OVA + poly(l:C); ${ }^{*}, P<.05 \mathrm{com}-$ pared to the PBS groups; ${ }^{* *}, P<.05$ compared to the other groups. (A) BAL cellularity in iNOS-deficient and WT (both C57BL/6 background) mice. (B) Representative lung histologies ( $a$ and $c, W T \_I C / O V A ; ~ b$ and d, iNOS KO_IC/OVA; H\&E staining; a and b: original magnification $\times 200$; $c$ and d: original magnification $\times 400$ ). (C) Levels of IP-10 and TGF- $\beta 1$ (left panel) and TNF- $\alpha$ (right panel) in the BAL fluids from iNOS-deficient and WT mice.

lung infiltration of inflammatory cells was significantly inhibited by $1400 \mathrm{~W}$ treatment, irrespective of dosage, as compared to sham treatment (Figure 6A). Evaluation of lung histology showed that peribronchiolar and perivascular infiltration of inflammatory cells was markedly decreased by $1400 \mathrm{~W}$ treatment, as compared to sham treatment (Figure 6B). In addition, the production levels of the downstream pro-inflammatory mediators IP-10, TGF- $\beta 1$, and TNF- $\alpha$ were significantly inhibited by $1400 \mathrm{~W}$ treatment, irrespective of the dosages used, as compared to sham treatment (Figure 6C). These findings indicate that drugs that target iNOS are good
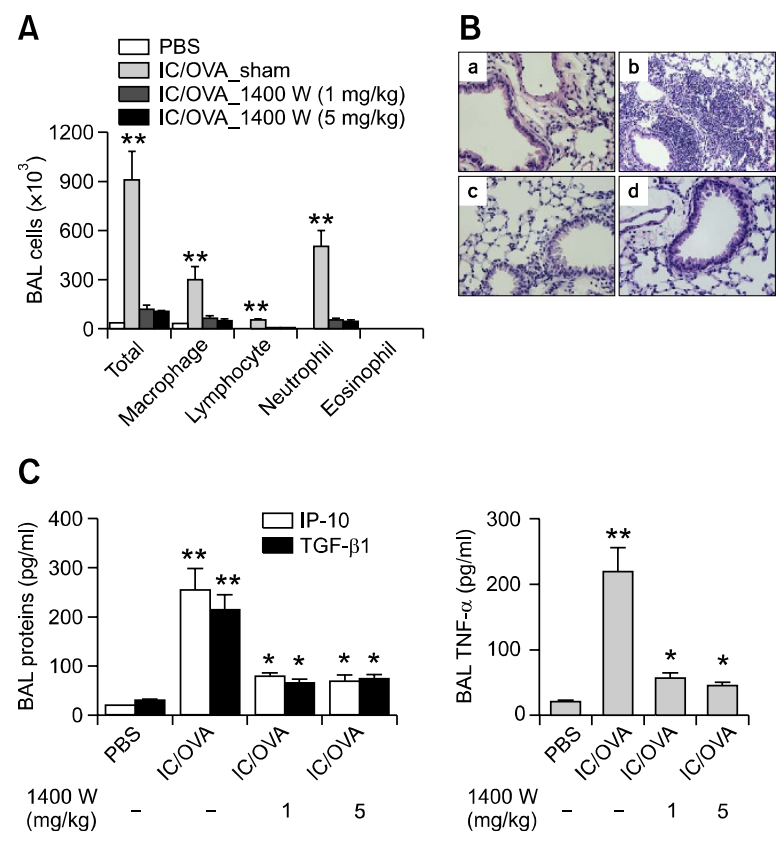

Figure 6. Treatment with a specific iNOS inhibitor (1400 W) abolishes lung inflammation induced by repeated allergen challenge with dsRNA. Evaluation ( $n=5$ per group) was performed $48 \mathrm{~h}$ after the final allergen challenge; PBS, mice sensitized with OVA and then challenged with PBS; IC/OVA, mice sensitized and challenged with OVA + poly $(\mathrm{I}: \mathrm{C}) ;{ }^{*}, P$ $<.05$ compared to PBS; ${ }^{* *}, P<.05$ compared to the other groups. (A) BAL cellularity in mice treated with different doses (1 and $5 \mathrm{mg} / \mathrm{kg}$ ) of 1400 W. (B) Representative lung histologies of mice treated with $1400 \mathrm{~W}$ (a, PBS; b, IC/OVA_sham; c, IC/OVA_1400 W (1 mg/kg); d, IC/OVA_1400 W (5 mg/kg); H\&E staining, original magnification $\times 400)$. (C) Levels of IP-10 and TGF- $\beta 1$ (left panel) and TNF- $\alpha$ (right panel) in the BAL fluids from mice treated with $1400 \mathrm{~W}$.

candidates for the treatment of asthma exacerbation during respiratory viral infections.

\section{Discussion}

Eosinophilic inflammation, which has long been considered as a distinctive pathologic hallmark of asthma, features in many contemporary definitions of this disease (Vignola et al., 1997). However, non-eosinophilic forms of asthma are relatively common (Jatakanon et al., 1999). There have been several reports of subgroups of asthmatic patients with persistent neutrophil-rich airway inflammation and lack of response to corticosteroids (Jatakanon et al., 1999; Gibson et al., 2001; Silvestri et al., 2006). Methodological advances, such as bronchoscopy and studies of induced sputum in severe asthma, have demonstrated that non-eosinophilic and even eosinophilic forms of severe asthma are associated with airway neutrophilia (Vrugt et al., 1999; Louis et al., 2000). Our previous data indicated that sputum neutro- 
phils, rather than eosinophils, were positively associated with asthma disease severity (Kim et al., 2007). Neutrophilic inflammation is also a characteristic feature of viral infections, which represent an important trigger of asthma exacerbation (Teran et al., 1997; Wark et al., 2002). These findings led to the notion that airway exposure to allergens during respiratory viral infections might induce exacerbation of lung inflammation than exposure to allergen alone. Indeed, in the present study, we showed that repeated allergen challenge together with dsRNA aggravated neutrophilic inflammation compared to allergen alone. Interestingly, neutrophilic inflammation enhanced by dsRNA was not only abolished in the absence of iNOS gene expression, but was also effectively blocked by treatment with the iNOS inhibitor $1400 \mathrm{~W}$. These results suggest that iNOS pathway plays an important role in the exacerbation of neutrophilic inflammation during respiratory viral infections.

Murine models of allergic asthma have traditionally comprised intraperitoneal sensitization with OVA using aluminum hydroxide as the adjuvant, followed by OVA challenges (Yang et al., 1995; Temelkovski et al., 1998). Although this type of model presents the characteristic features of asthma, i.e., extensive infiltration of eosinophils, subepithelial fibrosis, and airway hyperresponsiveness, it is not appropriate to evaluate mechanisms underlying neutrophilic inflammation seen in virusassociated asthma and/or viral infection-induced asthma exacerbation. The present study shows that the synthetic dsRNA analogue poly(l:C) enhances neutrophilic inflammation in the context of antigen inhalation. The increased total cell numbers and neutrophil numbers in the BAL fluids coincided with the elevation of Th1 (INF- $\gamma)$ and Th17 (IL-17) cytokines, and were attenuated by the abrogation of IFN- $\gamma$ or $I L-17$ gene expression. These findings suggest that Th17 cellular responses, together with Th1 cellular responses, play important roles in the development of neutrophilic inflammation in the model of virusassociated asthma exacerbation.

Although previous studies support the notion of Th1 cells and IFN- $\gamma$ as inhibitors of Th2 cellular responses, many studies have shown that Th1 cells enhance allergic inflammation (Hansen et al., 1999; Jeon et al., 2007b). For example, Dahl et al. reported that influenza $A$ infection incited a robust IFN- $\gamma$ response in the mouse lung, which promoted the development of IL-12-producing dendritic cells and subsequently enhanced Th1 and Th2 cellular responses (2004). Our previous studies showed that airway exposure to dsRNA plus allergens during sensitization enhanced antigen sensitization and IFN- $\gamma$ expression, and that these events were impaired in T-bet-deficient mice (Jeon et al., 2007b). IFN- $\gamma$ is known to activate macrophages and the surrounding structural cells, and to enhance the production of CXC chemokines, including IP-10 and IL-8, which preferentially attract monocytes, neutrophils, and activated lymphocytes (Boehm et al., 1997; Brightling et al., 2005; Silvestri et al., 2006). Moreover, transgenic over-expression of IFN- $\gamma$ in the airways induces non-eosinophilic inflammation and alveolar remodeling, such as emphysema (Wang et al., 2000). In the present study, we found that the production of IP-10 in the severe asthma model was completely abolished in the absence of IFN- $\gamma$ gene expression, which was accompanied by the inhibition of lung infiltration of inflammatory cells. These findings suggest that Th1 cellular responses induced by dsRNA-containing antigens are important events in the development of neutrophilic inflammation seen in asthma exacerbation during viral infections.

Th17 cells, which represent a new subset of T-helper cells, are named based on their production of the cytokine IL-17 (Bullens et al., 2006; Annunziato et al., 2007; Louten et al., 2009). These cells contribute to human chronic inflammatory diseases via the production of several pro-inflammatory cytokines (Jovanovic et al., 1998; Kotake et al., 1999; Iwakura and Ishigame, 2006). Furthermore, there is substantial evidence to suggest that Th17 cells are also involved in the airway inflammation associated with asthma (Kim et al., 2009). IL-17 orchestrates neutrophilic inflammation through the induction of pro-inflammatory mediators, such as TNF- $\alpha$, IL-1 $\beta$, IL-6, and CXCL8 (Laan et al., 1999). Indeed, the present study shows that neutrophilic inflammation in the virus-associated asthma exacerbation model is partly dependent upon IL-17, which is linked to the production of TNF- $\alpha$. These findings, together with up-regulation of TNF- $\alpha$ production by IFN- $\gamma$, suggest that TNF- $\alpha$ is a key player in the development of neutrophilic inflammation induced by Th17 cellular responses in the virus-associated asthma exacerbation model.

In general, nNOS and eNOS are expressed under physiologic conditions, whereas iNOS is regulated at the transcriptional level by the presence of pro-inflammatory stimuli, such as IFN- $\gamma$ and TNF- $\alpha$ (Chesrown et al., 1994; Dembinska-Kiec et al., 1997). The production of NO is increased in animal models of asthma, as well as in asthmatic patients (Kharitonov et al., 1995; Weicker et al., 2001). Respiratory viral infections are the predominant cause of exacerbations of 
asthma (Beasley et al., 2000). In the context of respiratory viral infections, NO plays an important role in the host defense owing to its potent antiviral properties (Schuh et al., 2002). Viral infection can lead to the activation of iNOS within the airway epithelium (Sagara et al., 2002). However, high levels of NO in the airways may be deleterious because they contribute to increased vascular permeability, mucus hypersecretion, epithelial cell damage, and inflammatory cell infiltration (Di Maria et al., 2000). The fact that iNOS is induced by IFN- $\gamma$ and TNF- $\alpha$ prompted us to explore whether iNOS is a good therapeutic target against the Th1 and Th17 cellular responses that mediate neutrophilic inflammation seen in asthma exacerbation during viral infections.

To assess the potential of NOSs as therapeutic targets against asthma exacerbation, we used pharmacologic and transgenic approaches to assess efficacy in the dsRNA-enhanced severe asthma model. The pharmacologic approach revealed that neutrophilic inflammation enhanced by dsRNA was inhibited by treatment with a nonspecific NOS inhibitor (L-NAME), but not with an eNOS-specific inhibitor (AP-CAV). This finding led us to evaluate iNOS as a therapeutic target against asthma exacerbation. The transgenic approach used in the present study revealed that neutrophilic inflammation in the asthma exacerbation model was abolished in the absence of iNOS gene expression. Furthermore, pharmacologic intervention with a specific iNOS inhibitor $(1400 \mathrm{~W})$ effectively inhibited development of neutrophilic inflammation induced by allergen exposure in combination with dsRNA. Taken together, these findings strongly suggest that iNOS is a good therapeutic target against the neutrophil-dominant asthma exacerbation that results from Th1 and Th17 cellular responses.

In summary, the present study shows that allergen challenge with the viral PAMP dsRNA induces a mixed Th1-type and Th17-type allergic inflammation, which is characterized by neutrophilic inflammation. Furthermore, we reveal iNOS as a potentially valuable therapeutic target for this type of severe inflammatory disease, which includes asthma exacerbation during respiratory viral infections.

\section{Methods}

\section{Animals}

C57BL/6 IFN- $\gamma$-deficient and C57BL/6 iNOS-deficient mice, as well as C57BL/6 and BALB/c wild-type (WT) mice were purchased from Jackson Laboratories (Bar Harbor, ME).
BALB/C IL-17-deficient and C57BL/6 IL-13-deficient mice were kindly donated by Y. C. Sung (POSTECH, Pohang, Republic of Korea) and by Z. Zhu (Johns Hopkins University, Baltimore, MD), respectively. Mice were bred in a pathogen-free facility at POSTECH, and all live animal experiments were approved by the POSTECH Ethics Committee.

\section{Reagents}

OVA and L-NAME were purchased from Sigma-Aldrich (St. Louis, MO). Poly(I:C) and $1400 \mathrm{~W}$ were purchased from Calbiochem (La Jolla, CA). AP-CAV peptide was synthesized by Peptron (Daejeon, Korea). For immunohistochemical staining, antibodies directed against eNOS (sc-654) and iNOS (sc-651) were purchased from Santa Cruz Biotechnology (Santa Cruz, CA).

\section{Protocol for the generation of a murine model of virus-associated asthma exacerbation}

To generate the virus-associated asthma model, mice were sensitized intranasally with $75 \mu \mathrm{g}$ OVA plus $10 \mu \mathrm{g}$ poly(I:C), as described previously (Jeon et al., 2007b). To generate a virus-associated severe asthma, sensitized mice were challenged with $50 \mu \mathrm{g}$ OVA with or without $10 \mu \mathrm{g}$ poly(l:C) twice weekly for 4 weeks as shown in Figure $1 \mathrm{~A}$. Pharmacologic intervention was performed during allergen challenge, and therapeutic efficacy was evaluated $48 \mathrm{~h}$ after the final allergen challenge.

\section{Evaluation of lung inflammation}

Lung and BAL samples were obtained, as previously described (Jeon et al., 2007a). The total numbers of inflammatory cells in the BAL fluids were assessed after staining with Diff-Quick (Dade Behring, Dudingen, Switzerland). For histology, Hematoxylin and eosin (H\&E) staining of lung sections was performed after pressure fixation with Streck solution (Streck Laboratories, Omaha, $\mathrm{NE})$.

\section{Fluorescent-activated cell sorting (FACS) analysis and intracellular cytokine staining}

To identify $T$ cells recruited into the lung, FACS analysis was performed using antibodies for a T-cell surface marker (anti-CD3). After preparation, single-cell-suspended $1 \times$ $10^{6}$ isolated cells were aliquoted into tubes and stained with FACS antibodies (BD Biosciences Pharmingen, San Diego, CA). To determine the intracellular cytokine levels, isolated lung cells were incubated at $37^{\circ} \mathrm{C}$ for $3 \mathrm{~h}$ in RPMI media containing $10 \%$ fetal bovine serum (FBS) and 2 $\mu \mathrm{g} / \mathrm{ml}$ brefeldin A (Sigma-Aldrich). Then the cells were washed in PBS containing 3\% FBS and $0.1 \%$ NaN3, followed by fixation in PBS containing $4 \%$ formaldehyde for $20 \mathrm{~min}$. After washing, the cells were permeabilized with $0.5 \%$ saponin (Sigma-Aldrich) in PBS for $10 \mathrm{~min}$, centrifuged, re-suspended in $50 \mu \mathrm{l}$ of the same solution, and stained with anti-IFN- $\gamma$, anti-IL-17, or anti-IL-4 antibodies for $30 \mathrm{~min}$. The cells were analyzed using the 
FACS Calibur system (BD Biosciences, Franklin Lakes, $\mathrm{NJ}$ ), and the results were processed using CellQuest software (BD Biosciences). The number of each type in the lung was determined by multiplying the total number of lung cells by the percentage of each cytokine-positive cells.

\section{Quantification of cytokines}

The levels of IP-10, TGF- $\beta 1$, and TNF- $\alpha$ in BAL fluids were measured by ELISA, in accordance with the manufacturer's instructions (R\&D Systems, Minneapolis, MN).

\section{Statistical analysis}

Significant differences between the treatments were assessed using the Student's $t$-test and ANOVA. For multiple comparisons, ANOVA was used initially, and when significant differences were found, individual $t$-tests for pairs of groups were performed.

\section{Acknowledgments}

We thank Zhou Zhu and Young-Chul Sung for their kind donations of IL-13- and IL-17-deficient mice, respectively, and Jee-In Lim for providing secretarial assistance. This study was supported by grant from the Korea Ministry of Health \& Welfare, Republic of Korea (A080711).

\section{References}

Alexopoulou L, Holt AC, Medzhitov R, Flavell RA. Recognition of double-stranded RNA and activation of NF-kappaB by Toll-like receptor 3. Nature 2001;413:732-8

Annunziato F, Cosmi L, Santarlasci V, Maggi L, Liotta F, Mazzinghi B, Parente E, Fili L, Ferri S, Frosali F, Giudici F, Romagnani P, Parronchi P, Tonelli F, Maggi E, Romagnani S. Phenotypic and functional features of human Th17 cells. J Exp Med 2007;204:1849-61

Bateman ED, Hurd SS, Barnes PJ, Bousquet J, Drazen JM, FitzGerald M, Gibson P, Ohta K, O'Byrne P, Pedersen SE, Pizzichini E, Sullivan SD, Wenzel SE, Zar HJ. Global strategy for asthma management and prevention : GINA executive summary. Eur Respir J 2008;31:143-78

Beasley R, Crane J, Lai CK, Pearce N. Prevalence and etiology of asthma. J Allergy Clin Immunol 2000;105: S466-72

Boehm U, Klamp T, Groot M, Howard JC. Cellular responses to interferon-gamma. Annu Rev Immunol 1997;15:749-95

Brightling CE, Ammit AJ, Kaur D, Black JL, Wardlaw AJ, Hughes JM, Bradding P. The CXCL10/CXCR3 axis mediates human lung mast cell migration to asthmatic airway smooth muscle. Am J Respir Crit Care Med 2005;171:1103-8

Bullens DM, Truyen E, Coteur L, Dilissen E, Hellings PW, Dupont LJ, Ceuppens JL. IL-17 mRNA in sputum of asthmatic patients: linking $T$ cell driven inflammation and granulocytic influx? Respir Res 2006;7:135
Busse WW, Lemanske RF Jr. Asthma. N Engl J Med 2001;344:350-62

Chesrown SE, Monnier J, Visner G, Nick HS. Regulation of inducible nitric oxide synthase mRNA levels by LPS, INFgamma, TGF-beta, and IL-10 in murine macrophage cell lines and rat peritoneal macrophages. Biochem Biophys Res Commun 1994;200:126-34

Dahl ME, Dabbagh K, Liggitt D, Kim S, Lewis DB. Viral-induced $T$ helper type 1 responses enhance allergic disease by effects on lung dendritic cells. Nat Immunol 2004;5:337-43

Dembinska-Kiec A, Dulak J, Partyka L, Krzesz R, Dudek D, Bartus S, Polus M, Guevara I, Wybranska I, Krzeminski T. Induction of nitric oxide synthase (NOS) and vascular endothelial growth factor (VEGF) in experimental model of angioplasty and heart ischemia. Adv Exp Med Biol 1997;433:163-7

Di Maria GU, Spicuzza L, Mistretta A, Mazzarella G. Role of endogenous nitric oxide in asthma. Allergy $2000 ; 55$ Suppl 61:31-5

Gibson PG, Simpson JL, Saltos N. Heterogeneity of airway inflammation in persistent asthma : evidence of neutrophilic inflammation and increased sputum interleukin-8. Chest 2001;119:1329-36

Grunig G, Warnock M, Wakil AE, Venkayya R, Brombacher F, Rennick DM, Sheppard D, Mohrs M, Donaldson DD, Locksley RM, Corry DB. Requirement for IL-13 independently of IL-4 in experimental asthma. Science 1998;282:2261-3

Guillot L, Le Goffic R, Bloch S, Escriou N, Akira S, Chignard $\mathrm{M}$, Si-Tahar M. Involvement of toll-like receptor 3 in the immune response of lung epithelial cells to double-stranded RNA and influenza A virus. J Biol Chem 2005;280:5571-80

Hansen G, Berry G, DeKruyff RH, Umetsu DT. Allergen-specific Th1 cells fail to counterbalance Th2 cellinduced airway hyperreactivity but cause severe airway inflammation. J Clin Invest 1999;103:175-83

Harkins MS, Fiato KL, Iwamoto GK. Exhaled nitric oxide predicts asthma exacerbation. J Asthma 2004;41:471-6

Iwakura $\mathrm{Y}$, Ishigame $\mathrm{H}$. The IL-23/IL-17 axis in inflammation. $\mathrm{J}$ Clin Invest 2006;116:1218-22

Jatakanon A, Uasuf C, Maziak W, Lim S, Chung KF, Barnes PJ. Neutrophilic inflammation in severe persistent asthma. Am J Respir Crit Care Med 1999;160:1532-9

Jeon SG, Lee CG, Oh MH, Chun EY, Gho YS, Cho SH, Kim JH, Min KU, Kim YY, Kim YK, Elias JA. Recombinant basic fibroblast growth factor inhibits the airway hyperresponsiveness, mucus production, and lung inflammation induced by an allergen challenge. J Allergy Clin Immunol 2007a;119:831-7

Jeon SG, Oh SY, Park HK, Kim YS, Shim EJ, Lee HS, Oh MH, Bang B, Chun EY, Kim SH, Gho YS, Zhu Z, Kim YY, Kim YK. $\mathrm{TH} 2$ and $\mathrm{TH} 1$ lung inflammation induced by airway allergen sensitization with low and high doses of double-stranded RNA. J Allergy Clin Immunol 2007b;120:803-12

Jovanovic DV, Di Battista JA, Martel-Pelletier J, Jolicoeur FC, 
He Y, Zhang M, Mineau F, Pelletier JP. IL-17 stimulates the production and expression of proinflammatory cytokines, IL-beta and TNF-alpha, by human macrophages. J Immunol 1998;160:3513-21

Karupiah G, Xie QW, Buller RM, Nathan C, Duarte C, MacMicking JD. Inhibition of viral replication by interferon-gamma-induced nitric oxide synthase. Science 1993;261:1445-8

Kato H, Takeuchi O, Sato S, Yoneyama M, Yamamoto M, Matsui K, Uematsu S, Jung A, Kawai T, Ishii KJ, Yamaguchi O, Otsu K, Tsujimura T, Koh CS, Reis e Sousa C, Matsuura Y, Fujita T, Akira S. Differential roles of MDA5 and RIG-I helicases in the recognition of RNA viruses. Nature 2006;441:101-5

Kharitonov SA, Yates D, Springall DR, Buttery L, Polak J, Robbins RA, Barnes PJ. Exhaled nitric oxide is increased in asthma. Chest 1995;107:156S-157S

Kim YK, Oh SY, Jeon SG, Park HW, Lee SY, Chun EY, Bang B, Lee HS, Oh MH, Kim YS, Kim JH, Gho YS, Cho SH, Min $\mathrm{KU}$, Kim YY, Zhu Z. Airway exposure levels of lipopolysaccharide determine type 1 versus type 2 experimental asthma. J Immunol 2007;178:5375-82

Kim YS, Hong SW, Choi JP, Shin TS, Moon HG, Choi EJ, Jeon SG, Oh SY, Gho YS, Zhu Z, Kim YK. Vascular endothelial growth factor is a key mediator in the development of $T$ cell priming and its polarization to type 1 and type $17 \mathrm{~T}$ helper cells in the airways. J Immunol 2009;183:5113-20

Kotake S, Udagawa N, Takahashi N, Matsuzaki K, Itoh K, Ishiyama S, Saito S, Inoue K, Kamatani N, Gillespie MT, Martin TJ, Suda T. IL-17 in synovial fluids from patients with rheumatoid arthritis is a potent stimulator of osteoclastogenesis. J Clin Invest 1999;103:1345-52

Kulka M, Alexopoulou L, Flavell RA, Metcalfe DD. Activation of mast cells by double-stranded RNA: evidence for activation through Toll-like receptor 3 . J Allergy Clin Immunol 2004; 114:174-82

Laan M, Cui ZH, Hoshino H, Lotvall J, Sjostrand M, Gruenert DC, Skoogh BE, Linden A. Neutrophil recruitment by human $\mathrm{IL}-17$ via C-X-C chemokine release in the airways. J Immunol 1999;162:2347-52

Louis R, Lau LC, Bron AO, Roldaan AC, Radermecker M, Djukanovic R. The relationship between airways inflammation and asthma severity. Am J Respir Crit Care Med 2000;161:9-16

Louten J, Boniface K, de Waal Malefyt R. Development and function of TH17 cells in health and disease. J Allergy Clin Immunol 2009;123:1004-11

Sagara H, Okada T, Okumura K, Ogawa H, Ra C, Fukuda T, Nakao A. Activation of TGF-beta/Smad2 signaling is associated with airway remodeling in asthma. J Allergy Clin Immunol 2002;110:249-54

Schuh JM, Power CA, Proudfoot AE, Kunkel SL, Lukacs NW, Hogaboam CM. Airway hyperresponsiveness, but not airway remodeling, is attenuated during chronic pulmonary allergic responses to Aspergillus in CCR4-/- mice. FASEB J 2002;16:1313-5

Sigurs N, Gustafsson PM, Bjarnason R, Lundberg F, Schmidt $S$, Sigurbergsson F, Kjellman B. Severe respiratory syncytial virus bronchiolitis in infancy and asthma and allergy at age 13. Am J Respir Crit Care Med 2005;171:137-41

Silvestri M, Bontempelli M, Giacomelli M, Malerba M, Rossi GA, Di Stefano A, Rossi A, Ricciardolo FL. High serum levels of tumour necrosis factor-alpha and interleukin-8 in severe asthma: markers of systemic inflammation? Clin Exp Allergy 2006;36:1373-81

Smith AD, Cowan JO, Brassett KP, Herbison GP, Taylor DR. Use of exhaled nitric oxide measurements to guide treatment in chronic asthma. N Engl J Med 2005;352:2163-73

Temelkovski J, Hogan SP, Shepherd DP, Foster PS, Kumar RK. An improved murine model of asthma: selective airway inflammation, epithelial lesions and increased methacholine responsiveness following chronic exposure to aerosolised allergen. Thorax 1998;53:849-56

Teran LM, Johnston SL, Schroder JM, Church MK, Holgate ST. Role of nasal interleukin-8 in neutrophil recruitment and activation in children with virus-induced asthma. Am J Respir Crit Care Med 1997;155:1362-6

Thomsen SF, van der Sluis S, Stensballe LG, Posthuma D, Skytthe A, Kyvik KO, Duffy DL, Backer V, Bisgaard $\mathrm{H}$. Exploring the association between severe respiratory syncytial virus infection and asthma: a registry-based twin study. Am J Respir Crit Care Med 2009;179:1091-7

Vignola AM, Chanez P, Chiappara G, Merendino A, Pace E, Rizzo A, la Rocca AM, Bellia V, Bonsignore G, Bousquet J. Transforming growth factor-beta expression in mucosal biopsies in asthma and chronic bronchitis. Am J Respir Crit Care Med 1997;156:591-9

Vrugt B, Wilson S, Underwood J, Bron A, de Bruyn R, Bradding P, Holgate ST, Djukanovic R, Aalbers R. Mucosal inflammation in severe glucocorticoid-dependent asthma. Eur Respir J 1999;13:1245-52

Wang Z, Zheng T, Zhu Z, Homer RJ, Riese RJ, Chapman HA $\mathrm{Jr}$, Shapiro SD, Elias JA. Interferon gamma induction of pulmonary emphysema in the adult murine lung. J Exp Med 2000;192:1587-600

Wark PA, Johnston SL, Moric I, Simpson JL, Hensley MJ, Gibson PG. Neutrophil degranulation and cell lysis is associated with clinical severity in virus-induced asthma. Eur Respir J 2002;19:68-75

Weicker S, Karachi TA, Scott JA, McCormack DG, Mehta S. Noninvasive measurement of exhaled nitric oxide in a spontaneously breathing mouse. Am J Respir Crit Care Med 2001;163:1113-6

Yang YL, Reis LF, Pavlovic J, Aguzzi A, Schafer R, Kumar A, Williams BR, Aguet M, Weissmann C. Deficient signaling in mice devoid of double-stranded RNA-dependent protein kinase. EMBO J 1995;14:6095-106 